Available online at GSC Online Press Directory

GSC Biological and Pharmaceutical Sciences

e-ISSN: 2581-3250, CODEN (USA): GBPSC2

Journal homepage: https://www.gsconlinepress.com/journals/gscbps

(REVIEW ARTICLE)

\title{
An insight of non-steroidal anti-inflammatory drug mefenamic acid: A review
}

\author{
Srivastava Rajat ${ }^{1,}$, Mishra Manoj Kumar ${ }^{1}$, Patel Amit Kumar ${ }^{1}$, Singh Abhishek ${ }^{1}$ and Kushwaha \\ Krishna $^{2}$
}

${ }^{1}$ Shambhunath Institute of Pharmacy, Jhalwa, Prayagraj, Uttar Pradesh, India-211012.

2 Lutawan Institute of Pharmacy, Sakara Jaitpura, Ghazipur, Uttar Pradesh, India-233001.

Publication history: Received on 14 April 2019; revised on 11 May 2019; accepted on 14 May 2019

Article DOI: https://doi.org/10.30574/gscbps.2019.7.2.0066

\begin{abstract}
This review focuses on the design, synthesis and pharmacological effects of non-steroidal anti-inflammatory (NSAIDs) mefenamic acid which is an anthranilic acid derivative. Mefenamic acid is a non-steroidal anti-inflammatory drug used to treat pain, including menstrual pain. Exploitation of the prodrug approach has the potential to achieve a reduction of mefenamic acid GI (gastrointestinal) intolerance, enhance its bioavailability, mask its unpleasant sensation and prolong its duration of action. Mefenamic acid, an effective NSAID has always been used as an anti-inflammatory and analgesic agent. A brief note on various marketed formulations of mefenamic acid provides an insight of the potential capability of this drug and its future scope.
\end{abstract}

Keywords: Anti-inflammatory drugs; Mefenamic acid; Rheumatoid arthritis; Dosage formulations

\section{Introduction}

Mefenamic acid (MA) is an anthranilic acid derivative. In particular, it is structured as $N$-(2,3-xylyl) anthranilic acid. This drug shares relatedness to 3-hydroxyanthranilic acid, a naturally occurring metabolite of tryptophan [1].

Its physicochemical properties, especially the extremely low solubility in water $\left(<<1 \mathrm{mg} \mathrm{mL}^{-1}\right)$ and distinct adhesive properties give rise to major challenges during dosage form development and manufacturing. Hence, serious effort was made to increase dissolution characteristics of MA to improve its biopharmaceutical performance [2].

The short biological half- life of Mefenamic acid is $2 \mathrm{~h}$. Conventionally it is available as tablets, capsules and suspensions. Because of short half-life oral dose required to frequent administration of drug to maintain the desired steady state level. The available dose for this drug is $250 \mathrm{mg}$ thrice a day. MA is classified as class II on the basis of biopharmaceutical classification system, because of its poor solubility over the $\mathrm{pH}$ range 1.2-7.5. It is inherently highly permeable through biological membranes, but exhibits low aqueous solubility. Due to its low solubility, various researches were done to improve the low solubility or bioavailability such as solid dispersion and micronization. Mefenamic acid is widely used in mild to moderate pain including headache, dental pain, dysmenorrhea, rheumatoid arthritis, osteoarthritis and other joint disorders also leads to side effects such as gastrointestinal disorders, like gastrointestinal bleeding and gastric upset.

Drug delivery at specific site is affected by carriers used. Carrier used should be biocompatible and immunogenic in nature. Also, suitable for route administration and desired release profile of drug. Eudragit RL 100 and Ethyl cellulose have been used as drug carriers to achieve sustained and controlled drug delivery for the past few decades [3].

\footnotetext{
${ }^{*}$ Corresponding author

E-mail address: rajatb.srivastava@gmail.com
} 
<smiles>Cc1cccc(Nc2ccccc2C(=O)O)c1C</smiles>

Figure 1 Structure of mefenamic acid

Table 1Characteristic feature of mefenamic acid

\begin{tabular}{ll}
\hline Characteristic feature & Description \\
\hline Molecular formula & $\mathrm{C}_{15} \mathrm{H}_{15} \mathrm{NO}_{2}$ \\
Molecular weight & 241.28 \\
Chemical name & $2-[(2,3-$ dimethylphenyl)amino]benzoic acid \\
Volume of distribution & $1.06 \mathrm{~L} / \mathrm{kg}$ \\
Protein binding & $90 \%$ \\
Half life & $2 \mathrm{~h}$ \\
LD50 & $740 \mathrm{mg} / \mathrm{kg}$ \\
Solubility & $0.0137 \mathrm{mg} / \mathrm{mL}$ \\
log P & 5.4 \\
pKa & 3.89 \\
Refractive index & $71.88 \mathrm{~m} 3 . \mathrm{mol}-1$ \\
Melting point & $230-231$ \\
Color & White to off-white, crystalline powder \\
Boiling point & 398.8 \\
Density & $1.2 \mathrm{gm} / \mathrm{cm}$ \\
Molar volume & $200.6 \mathrm{~cm}$ \\
\hline
\end{tabular}

\subsection{Mode of action}

MA binds the prostaglandin synthetase receptors COX-1 and COX-2, inhibiting the action of prostaglandin synthetase. As these receptors have a role as a major mediator of inflammation and/or a role for prostanoid signaling in activitydependent plasticity, the symptoms of pain are temporarily reduced.

Cox-1: Cyclooxygenase-1, an enzyme that acts to speed up the production of certain chemical messengers, called prostaglandins, in a variety of areas of the body such as the stomach, kidneys, and sites of inflammation. In the stomach, prostaglandins promote the production of a protective natural mucus lining. They also interact within certain cells that are responsible for inflammation and other functions.

Cox-2: Cyclooxygenase-2, an enzyme that acts to speed up the production of certain chemical messengers, called prostaglandins that play a key role in promoting inflammation. When cox- 2 activity is blocked, inflammation is reduced. Unlike cox-1, cox-2 is active only at the site of inflammation, not in the stomach.

\subsection{Pharmcokinetics}

\subsubsection{Absorption}

Mefenamic acid is rapidly absorbed after oral administration. Mean extent of absorption was $30.5 \mathrm{mcg} / \mathrm{h} / \mathrm{mL}$. 


\subsubsection{Distribution}

Apparent volume of distribution was found to be $1.06 \mathrm{~L} / \mathrm{Kg}$ for $500 \mathrm{mg}$ tablet.

\subsubsection{Metabolism}

Mefenamic acid is metabolized by cytochrome P450 enzyme CYP2C9 to 3-hydroxylmethylmefenamic acid (Metabolite I). Further oxidation to a 3- carboxymefenamic acid (Metabolite II) may occur.

\subsubsection{Excretion}

Approximately $52 \%$ of a mefenamic acid dose is excreted into urine primarily as glucuronides of mefenamic acid (6\%), 3- hydroxymefenamic acid (25\%) and 3- carboxymefenamic acid (21\%). The fecal route of elimination accounts for up to $20 \%$ of the dose. The elimination half-life of mefenamic acid is approximately $2 \mathrm{~h} \mathrm{[4].}$

\subsection{Drug interaction}

(R)-warfarin: the risk or severity of gastrointestinal bleeding can be increased.

(S)-Warfarin:The risk or severity of gastrointestinal bleeding can be increased.

2, 5-Dimethoxy-4-ethylamphetamine: The risk or severity of hypertension can be increased.

4-Bromo-2, 5-dimethoxyamphetamine: The risk or severity of hypertension can be increased.

4-hydroxycoumarin: The risk or severity of gastrointestinal bleeding can be increased.

\subsubsection{Side effect}

- Cardiovascular thrombotic

- GI Bleeding, Ulceration

- Hepatotoxicity

- Hypertension

- Renal toxicity and Hyperkalemia

- Serious skin reaction

- Hematologic toxicity

\subsubsection{Contraindication}

- Methotrexate- Neutopenia, Renal dysfunction,

- Aspirin- GI bleeding, Ulceration

- Cyclosporine- Increase cyclosporine's nephrotoxicity

- Other NSAIDs- GI bleeding, Ulceration

\section{Formulations of mefenamic acid}

The suitable formulation for the synthesized drugs is always a challenge for the researchers. The compatibility of all the components including pharmaceutical active ingredients plays significant role in designing the formulation so always it is taken into consideration. The developed formulation should be cost effective, stable and physiologically the active ingredients should be available on release [5].

\subsection{Mefenamic acid suspension}

Drugs dispensed as suspensions because of poor aqueous solubility (BCS class II). Drug formulated as suspensions are more bioavailable than solid dosage form [6]. Possible modification of the drug's bioavailability can be another advantage of this dosage form, The prodrugs were already reported as chemically stable and bio-labile so for the suspension first there is preparation of prodrug of mefenamic acid which results in delayed drug release, provides clinically useful plasma concentration of the drug [7]. 


\subsubsection{Material}

Mefenamic acid, Tween-80, Potassium chloride, Methyl cellulose, Sodium CMC, Sodium citrate, Sodium benzoate, Glycerine, etc.

\subsubsection{Preparation of suspensions of prodrugs}

The weighed quantities of prodrugs were wetted by trituration with aqueous solution of wetting agent. Glycerin was added by trituration to form smooth paste. Now water soluble ingredients (sodium citrate, sodium benzoate) were dissolved in water and added slowly and triturated. Potassium chloride dissolved in water added with trituration. Thereafter aqueous solution of suspending agent and syrup was added to above mixture with trituration. Then flavor was added and mixed. The suspension so formed transferred to a measuring cylinder and volume was made to $100 \mathrm{~mL}$.

Table 2List of marketed products of Mefenamic acid suspension

\begin{tabular}{lll}
\hline Sr. No. & Marketed product (Brand name) & Manufacturing company \\
\hline 1 & Meftal-P & Blue I Cross Laboratories \\
2 & Paramol-M & Parkinson Pharma \\
3 & Panston & Pfizer \\
4 & Meftagesic & Blue Cross Laboratories \\
5 & Alide P & Altar Life Sciences \\
6 & Nimucet MF & Intas laboratories Pvt. Ltd. \\
7 & Zuesic Forte & Zodak Health Care Ltd. \\
8 & M Gesic & Cure Quick Remedies \\
9 & Pyritec M DS & Innovative Pharmaceuticals \\
10 & Parafit M & Medlab Pharmaceuticals Pvt. Ltd. \\
\hline
\end{tabular}

\subsection{Controlled release tablets containing mefenamic acid}

Oral drug delivery system have the advantages that these are easy to administer, ease of manufacturing and higher patient compliance. In oral drug delivery systems the most profound objective was to maintain constant drug plasma concentrations for a certain period of time to reduce the dosage frequency and this goal achieved by the development of controlled drug delivery system [8].

Oral sustain/controlled release drug delivery systems is dominating the market and have an increased safety and patient compliance. These dosage forms can deliver the drug in a predetermined manner to the site of action following drug release from matrices occurs by diffusion or degradation mechanism.

- Polymers, Polyurethanes for elasticity.

- Polysiloxanes or silicones for insulating ability.

- Polymethyl methacrylate for physical strength and transparency.

- Polyvinyl alcohol for hydrophilicity and strength.

- Polyethylene for toughness and lack of swelling.

- Polyvinyl pyrrolidone for suspension capabilities.

To be successfully used in controlled drug delivery formulations, a material must be chemically inert and free of leachable impurities, controls release of drug in a slow and nearly constant manner to obtain nearly constant peak plasma level $[9,10]$. 


\subsubsection{Material}

Mefenamic acid, sodium hydroxide, mono basic potassium phosphate, caboxy methyl cellulose, starch, lactose and magnesium stearate.

\subsubsection{Formulation of tablets}

Mefenamic acid $200 \mathrm{mg}$ controlled release matrix tablets were prepared using $100 \mathrm{mg}$ drug and weighing concentrations of polymer and excipients. Starch was used as filler and magnesium stearate was used a lubricant.

\subsubsection{Preparation of tablets}

Drug and polymer was taken in mortar and was grind to fine powder than all other excipients were added except lubricant. This mixture was passed through 20 sieve size mesh for three times and then lubricant was added and again passed through the same sieve. The prepared powder was compressed to tablets using single punch tabletting machine at an average hardness of $7 \mathrm{~kg} / \mathrm{cm}^{2}$.

Table 3List of marketed products of Mefenamic acid tablet

\begin{tabular}{lll}
\hline $\begin{array}{l}\text { Sr. } \\
\text { No. }\end{array}$ & $\begin{array}{l}\text { Marketed products } \\
\text { (Brand name) }\end{array}$ & Manufacturing company \\
\hline 1 & Abdrot Plus & CaptabBiotec \\
2 & Alide-P & Altar Pharma \\
3 & MefProxyvon & Wockhardt \\
4 & Meflup & Lupin \\
5 & Meflup Forte & Lupin \\
6 & Ponstan & Pfizer \\
7 & Meftal 500 & Blue Cross Laboratories \\
8 & Biospas Forte & Biochem \\
9 & Mictal 250 & Biochem \\
10 & Meff P & Bastochem \\
\hline
\end{tabular}

\subsection{Mefenamic acid emulgel for topical delivery}

Gels are a relatively newer class of dosage form created by entrapment of large amounts of aqueous or hydroalcoholic liquid in a network of colloidal solid particles, which may consist of inorganic substances, such as aluminum salts or organic polymers of natural or synthetic origin. They have a higher aqueous component that permits greater dissolution of drugs, and also permit easy migration of the drug through a vehicle that is essentially a liquid, compared with the ointment or cream base. In spite of many advantages of gels a major limitation is in the delivery of hydrophobic drugs [11].

So to overcome this limitation, emulgels are prepared and used so that even a hydrophobic therapeutic moiety can enjoy the unique properties of gels [12]. When gels and emulsions are used in combined form the dosage forms are referred as EMULGELS [13].

In recent years, there has been great interest in the use of novel polymers with complex functions as emulsifiers and thickeners because the gelling capacity of these compounds allows the formulation of stable emulsions and creams by decreasing surface and interfacial tension and at the same time increasing the viscosity of the aqueous phase [14]. Emulgels for dermatological use have several favorable properties such as being thixotropic, greaseless, easily spreadable, easily removable, emollient, non-staining, long shelf life, bio-friendly, transparent and pleasing appearance [15].

\subsubsection{Material}

Mefenamicacid, carbopal 940, liquid paraffin, tween 20, span20, propylene glycol, methyl paraben, ethyl paraben, mentha oil, clove oil, water. 


\subsubsection{Preparation of emulgel}

The gel phase in the formulations was prepared by dispersing Carbopol 940 in purified water with constant stirring at a moderate speed using mechanical shaker, then the $\mathrm{pH}$ was adjusted to 6-6.5 using tri ethanol amine (TEA). The oil phase of the emulsion was prepared by dissolving span 20 in light liquid paraffin while the aqueous phase was prepared by dissolving tween 20 in purified water. Methyl and ethyl parabens were dissolved in propylene glycol whereas mefenamic acid was dissolved in ethanol, and both solutions were mixed with the aqueous phase. Clove oil and mentha oil were mixed in oil phase. Both the oily and aqueous phases were separately heated to $70-80^{\circ} \mathrm{C}$, then the oily phase was added to the aqueous phase with continuous stirring until it got cooled to room temperature. The obtained emulsion was mixed with the gel in 1:1 ratio with gentle stirring to obtain the emulgel [16].

Table 4 List of marketed products of NSAIDS emulgel

\begin{tabular}{lll}
\hline Sr. No. & Marketed products (Brand name) & Manufacturing company \\
\hline 1 & Volini GEL & Ranbaxy Laboratories \\
2 & DiclonEmulgel & Med Pharma \\
3 & Voltaren & Novartis Pharma \\
4 & Voltarol Emulgel P & Glaxo Smith Kline Pharma \\
5 & Isofen Emulgel & Beitjala Pharma \\
\hline
\end{tabular}

\subsection{Topical gel containing microsponges of mefenamic acid}

The microsponge delivery system is patented polymeric system consisting of porous microsphere. They are tiny sponge like spherical particles that consist of myriad of inter connecting void within a non-collapsible structure through which active ingredient are released in a controlled manner. Microsphere surrounded by the vehicle acts like microscopic sponges, storing the active ingredient until its release is triggered by skin application. Release of drug into the skin is triggered by a variety of stimuli, including rubbing and higher skin temperature than ambient one. Their high degree of cross linking results in particles that are insoluble, inert and of sufficiently strong strength to withstand the high shear commonly used in creams, lotions, and powders $[17,18]$.

The microsponges were prepared by free radical suspension method or quassi emulsion solvent diffusion method. It was shown that the drug: polymer ratio, stirring rate, volume of dispersed phase influenced the particle size and drug release behavior of the formed microsponges and that the presence of emulsifier was essential for microsponge formation [19].

\subsubsection{Material}

Mefenamicacid, eudragit RS100, eudragit RL 100, ethyl cellulose, polyvinyl alcohol, ethanol, carbopol 934P, triethaolamine, distilled water

\subsubsection{Formulation of mefenamic acid loaded microsponges}

Microsponge were prepared by quasi-emulsion solvent diffusion method using an external phase of distilled water and polyvinyl alcohol (PVA), and internal phase consisting of drug, ethyl alcohol, polymer(ethyl cellulose, eudragit RS100 \& eudragit RL 100) and glycerol (which was added at an amount of $20 \%$ of the polymer in order to facilitate the plasticity). For preparing microsponge, the internal phase was prepared and added to the external phase at room temperature. After emulsification process is completed, the mixture was continuously stirred for $2 \mathrm{~h}$ at $500 \mathrm{rpm}$. Then the microsponges were separated by filtration. The product was washed and dried under vacuum oven at $40^{\circ} \mathrm{C}$ for $12 \mathrm{~h}[20$, 21].

\subsubsection{Mefenamic acid microsponge gel}

Accurately weighed amount of carbopol $934 \mathrm{P}$ was taken and dissolved in water using propeller. Microsponge formulations containing mefenamic acid was added to the above solution with constant stirring. This final solution was neutralized slowly adding triethanolamine with constant stirring until the gel is formed [22]. 
Table 5List of other marketed products of Mefenamic acid

\begin{tabular}{lll}
\hline Sr. No. & Marketed products (Brand name) & Manufacturing company \\
\hline 1 & Mefpra (Syrup) & Immune Life Sciences \\
2 & Ladex P (Syrup) & Allenge India \\
3 & Migesic (Syrup) & Hauz Pharma Pvt. Ltd. \\
4 & Nimley P (Syrup) & Zodley Pharmaceutical Pvt. Ltd. \\
5 & Zuesic P (Syrup) & Zodak Health Care \\
6 & Nukind M (Syrup) & Ambic Aayurchem \\
7 & Mifucet (Suppository) & Intas Pharmaceuticals Ltd. \\
8 & Armef Forte (Capsule) & Ardor Drugs Pvt. Ltd. \\
\hline
\end{tabular}

\section{Conclusion}

Mefenamic acid, a BCS class II drug gives a reason to improve its solubility and by studying about its formulations it gives major goal for formulation development of modified drug delivery system such as Nanocrystals, Nanostructured lipid carriers etc. for improved bioavailability of the drug at desired site of action.

\section{Compliance with ethical standards}

\section{Acknowledgments}

All authors are highly grateful to their respective management for encouraging this work.

\section{Disclosure of conflict of interest}

The review article bears no conflict of interest.

\section{References}

[1] Winder CV. (1966). Experimental observations on flufenamic, mefenamic, and meclofenamic acids. I. Pharmacology. Annals of Physical and Rehabilitation Medicine, Suppl. 7-16.

[2] Sriamomsak P, Limmatvapirat S, Piriyaprasarth S, Mansukmanee P and Huang Z. (2015). A new emulsifying formulation of mefenamic acid with enhanced drug dissolution. Asian Journal of Pharmaceutical Sciences, 10(2), 121-127.

[3] Patel KC and Pramanik S. (2014). Formulation and characterization of Mefenamic acid loaded polymeric nanoparticles. World Journal of Pharmacy and Pharmaceutical Sciences, 3(6), 1391-1405.

[4] Shah K, Shrivastava SK and Mishra P. (2014). Formulation and evaluation of suspensions: Mefenamic acid prodrugs. Pakistan Journal of Pharmaceutical Sciences, 27(4), 917-923.

[5] Ansel HC and Popovish NK (1995). Pharmaceutical dosage forms and drug delivery system, sixth edition. BI Waverly Pvt. Ltd., New Delhi, India, 253-254.

[6] Shah K, Shrivastava SK and Mishra P. (2013). Evaluation of mefenamic acid mutual prodrugs. Medicinal Chemical Research, 22(1), 70-77.

[7] Usman M, Ali I, Bibi H, Iqbal J and Iqbal K. (2012) Preparation and evaluation of controlled release tablets containing Mefenamic acid. Journal of Clinical and Experimental Pharmacolology, 2(1), 107.

[8] Kumar L and Verma R. (2010). In vitro evaluation of topical gel prepared using natural polymer. International Journal of Drug Delivery 2, 58-63. 
[9] Shah SU, Shah KU, Rehman A and Khan GM. (2011). Investigating the in vitro drug release kinetics from controlled release diclofenac potassium-ethocel matrix tablets and the influence of co-excipients on drug release patterns. Pakistan Journal of Pharmaceutical Sciences, 24(2), 183-192.

[10] Khullar R, Kumar D, Seth N and Saini S. (2012). Formulation and evaluation of mefenamic acid emulgel for topical delivery. Saudi Pharmaceutical Journal, 20(1), 63-67.

[11] Steiger M. (2004).Topical emulsion, gel composition comprising diclofenac sodium. European Patent Specification no. WO/2004/017998).

[12] Mohamed MI. (2004). Optimization of chlorphenesinemulgel formulation. AAPS Journal, 6 (3), 81-87.

[13] Gupta A, Mishra AK, Singh AK, Gupta V and Bansal P. (2010). Formulation and evaluation of topical gel of diclofenac sodium using different polymers. Drug Invention Today, 2(5), 250-253.

[14] Stanos, SP. (2007). Topical agents for the management of musculoskeletal pain. Journal of Pain Symptom Management, 33(3), 342-355.

[15] Jain A, Deveda P, Vyas N, Chauhan J, Khambete H and Jain S. (2011). Development of antifungal emulsion based gel for topical fungal infection(s). International Journal of Pharmaceutical Research and Development, 2 (12), 1825.

[16] Shuhaib B and Suja C. (2019).Studies on formulation and characterization of topical emulgel containing microsponges of mefenamic acid. European Journal of Pharmaceutical and Medical Research, 6(1), 314-326.

[17] Embil K and Nacht S. (1996). The microsponge delivery system (MDS): a topical delivery system with reduced irritancy in-cooperating multiple triggering mechanism for the release of actives. Journal of Microencapsulation, 13(5): 575-588.

[18] Comoglo T, Gonul N and Baykara T. (2003). Preparation and in vitro evaluation of modified release ketoprofen microsponges. Farmaco, 58(2), 101-106.

[19] Ali N, Mitra J, Mohammad-Reza S and Siavoosh D. (2005). The effect of formulation type on the release of benzoyl peroxide from microsponges. Iranian Journal of Pharmaceutical Sciences, 1(3), 131-142.

[20] Mahaparale PR, Nikam SA and Chavan MS. (2018). Development and evaluation of terbinafine hydrochloride polymeric microsponges for topical drug delivery. Indian Journal of Pharmaceutical Sciences, 80(6), 1086-1092.

[21] Mandava SS and Thavva V. (2014). Novel approach: microsponge drug delivery system. International Journal of Pharmaceutical Sciences and Research, 3(4), 967-980.

[22] Swetha A, Rao GM, Ramana VK, Niyaz BB and Reddy KV. (2011). Formulation and in vitro evaluation of etodolac entrapped in microsponge based drug delivery system. International Journal of Pharmacy, 1(2) 73-80.

\section{How to cite this article}

Srivastava R, Mishra MK, Patel AK, Singh A and Kushwaha K. (2019). An insight of non-steroidal anti-inflammatory drug mefenamic acid: A review. GSC Biological and Pharmaceutical Sciences, 7(2), 52-59. 